\title{
DISCARDED TYRE RUBBER AS CONCRETE AGGREGATE: A POSSIBLE OUTLET FOR USED TYRES
}

\author{
M. MAVROULIDOU * \\ J. FIGUEIREDO
}

\author{
Department of Urban Engineering,
London South Bank University, \\ Lepartment of Urban Engineering,
London South Bank University, \\ 103 Borough Road, London, SE1 OAA, UK
}

*to whom all correspondence should be addressed:

e-mail: mavroum@lsbu.ac.uk
Received: 20/02/09

Accepted: 21/09/10

\begin{abstract}
Discarded vehicle tyres constitute one important part of solid waste which had historically been disposed of into landfills. Recent EU policies on the Landfilling of Waste (Council Directive 1999/31/EC) have however put a ban on the landfilling of whole or shredded tyres, creating an imminent need to investigate any possible viable uses of this waste product. An emerging use is the production of concrete, in which tyre rubber particles partially replace natural aggregates. This has the additional advantage of saving in natural aggregates used in the production of concrete which are becoming increasingly scarce. This research investigated a wide range of physical and mechanical properties of concrete containing recycled tyre aggregates, to assess its suitability as a construction material. The influence of factors such as rubber aggregate content and size, as well as curing time was also considered. The results showed that despite a great loss in strength, this type of concrete was acceptable for various applications requiring medium to low compressive strength. The quantities of concrete produced worldwide for such applications could ensure the viability of this product. Therefore, this type of concrete shows promise for becoming an additional sustainable solution for tyre rubber waste management.
\end{abstract}

KEYWORDS: solid waste management, used vehicle tyres, rubberised concrete properties.

\section{INTRODUCTION}

Municipal solid waste management practices in the UK are currently going through a period of rapid evolution, due to the EU Directive on the Landfilling of Waste (Council Directive 1999/31/EC), which has been transposed to the UK through the Landfill Regulation. It is based on the policy objective to manage resources in a more sustainable manner, and adopt strategies for reducing waste at the source by recycling. Discarded vehicle tyres constitute one important part of solid waste which has historically been disposed of into landfills. It is estimated that in the UK about 40 million tyres per year (i.e. more than 100,000 tyres per day) have been ending up as waste. This number is expected to increase by a further $63 \%$ by 2021, due to the forecasted growth in road traffic (Cairns et al., 2004). This has become a major solid waste disposal problem in the UK. Tyre disposal to landfills is problematic, as waste rubber is not easily biodegradable. Stockpiled tyres also present many health, environmental and economic risks through air, water and soil pollution, littering the landscape, and providing a breeding habitat for various pests. Moreover, tyres present serious fire hazards: once set alight they burn fiercely, producing a number of chemicals harmful to the environment. This can cause considerable air, water as well as soil pollution. A number of such major tyre fires have already occurred in the UK with severe adverse environmental impacts. A well-known example is that of Heyope in Powys, Wales, where the largest landfill site in Britain for such scrap tyres was located (this held over 9,000,000 tyres). In 1989 an intense fire took hold deep inside the mass of scrap tyres and had subsequently been burning for eleven years. This caused extensive pollution to the atmosphere and the local water system (Bateman, 2002). It is therefore clear that better ways of managing tyres and waste in general are required. Recent EU policies on the Landfilling of Waste (Council Directive 1999/31/EC) have therefore put a ban on the landfilling of whole or shredded tyres, creating an imminent need to investigate any possible viable uses of this waste product. There are various potential ways to reduce the need for tyre disposal. These include amongst other: a) retreading and reuse 
of old tyres; b) use as a fuel in addition or as a replacement to more conventional fuels (coal and petroleum coke) and c) shredding or grinding tyres for use in rubberised playground and sports field surfaces, roadways and drainage schemes etc. An emerging field for the reuse of scrap tyres is in the production of concrete, where tyre rubber can be used as a partial replacement to natural aggregates. This has the additional advantage of saving in natural resources. Shredded or ground tyres are different to other waste materials with a potential for re-use, because their production method is now well developed. Hence, the reuse of this material in concrete could have both environmental advantages and the same time ensure economic viability. However, for concrete with scrap tyre aggregate to be considered as a construction material, the minimum requirements of strength and durability should be met. This has recently been the subject of a number of studies but the area is still relatively less researched than the use of tyres in the other applications mentioned above. A literature review into this area which showed that at the time of this research, there was still a relatively limited amount of information for some properties of this type of material and some contradictory or inconclusive results across the existing literature. For instance, some researchers found that mixing rubber aggregate of coarse grading resulted in higher compressive strength losses than aggregate of finer grading (Eldin and Senouci, 1993; Topçu, 1995). Conversely others (e.g. Fattuhi and Clark, 1996 or Ali et al., 2000) found the opposite trend. Moreover, sizes and types of rubber aggregate used varied across researchers. It is therefore difficult to reach consistent conclusions about various properties at various curing times coming from different literature sources. This research therefore aimed at performing a set of consistent tests for a wide range of physical and mechanical properties and behaviour of concrete containing rubber aggregate. These are presented in detail in the following sections.

\section{EXPERIMENTAL PROCEDURE, MATERIAL AND MIXES}

For this experiment scrap tyre aggregates ranging from 20-1 mm were obtained from McGrath Bros. These are meant to be used in particular for equestrian circuits. According to information obtained from the supplier, these contain mostly textile fibre rather than steel fibre however the latter could amount to $5 \%$ of the total rubber tyre aggregate. The material was sieved and split into two groups of tyre aggregate: coarse rubber aggregate $(19-10 \mathrm{~mm})$ and fine rubber aggregate material $(10-4.75 \mathrm{~mm})$. These groups will be referred to as CRA (Coarse Rubber Aggregates) and FRA (Fine Rubber Aggregates). The shape of the rubber aggregate was observed to be sub-angular. Figure 1 shows the particle size distribution curves for the two groups of rubber aggregates (coarse and fine aggregate groups) together with those of the mineral aggregates which were used in the test and were partly replaced by the rubber aggregates. The mineral aggregates are referred to as CMA (Coarse Mineral Aggregates) and FMA (Fine Mineral Aggregates). It is noticeable that the particle size distribution of the rubber aggregates is very close to that of the respective mineral aggregates (coarse or fine) conforming to BS 882 (BSI, 1992) and satisfying the aggregate grading requirements.

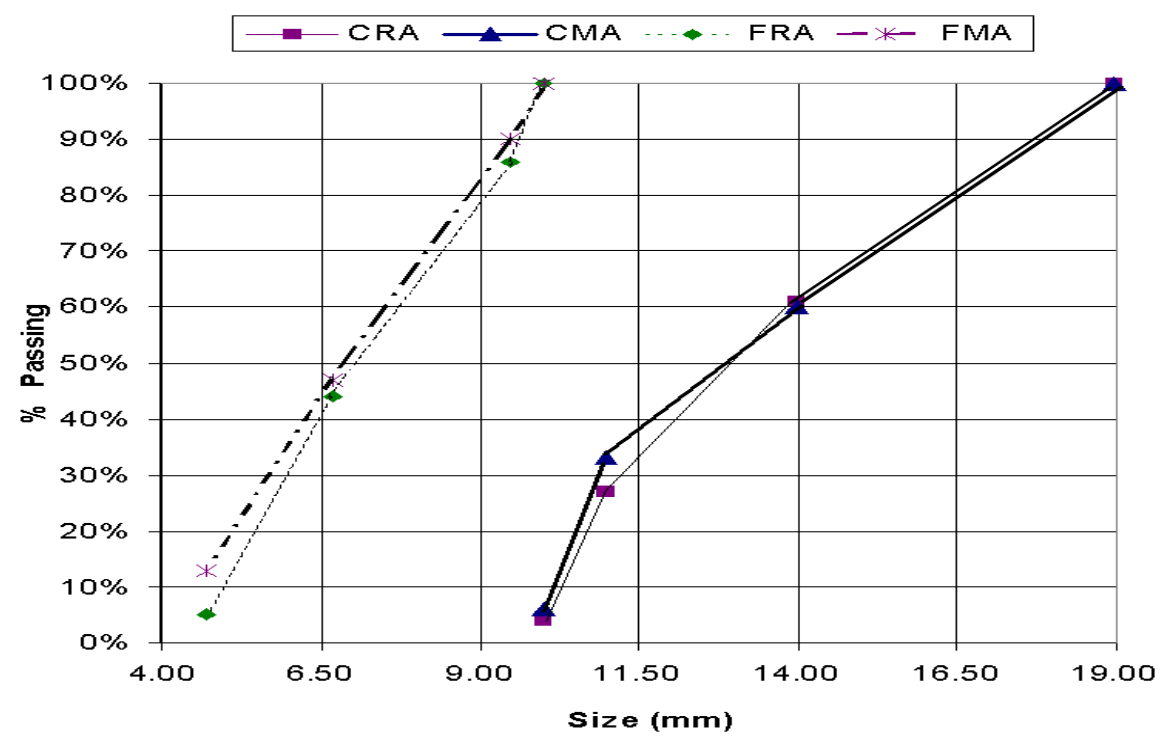

Figure 1. Particle size distribution of rubber and mineral aggregates used in the mixes

Ordinary Portland cement mix was used as the control mix (referred to as $\mathrm{CM}$ ) for the purposes of comparison. This consisted of 1 part cement; 1.5 parts sand and 3 parts coarse aggregate (1:1.5:3). The 
mix design was according to BS 5328: Part 1 guidelines for RC40 (BSI, 1997). Two sets of mixes including rubber aggregate were then prepared for each test. In the first set of mixes, the coarse rubber aggregate (CRA) replaced part of the coarse mineral aggregate (CMA) of the control mix. In the second, fine rubber aggregate (FRA) replaced partly fine mineral (stone) aggregate (FMA) of the control mix. Four different contents of rubber aggregate (by mass) were used to replace the mineral aggregate $(10 \%, 20 \%, 30 \%$ and $40 \%$ respectively). The dry material comprising cement, sand, aggregate and rubber was well mixed before the water was gradually included. The water/cement ratio was kept constant (i.e. w/c $=0.55$ ) for all samples for consistency in the comparisons. The workability of all fresh mixes was then assessed using the slump test. The specimens were then placed in moulds and compacted. It should be noted that some difficulties were experienced during hand compaction of the samples (using a standard rammer) due to the tyre aggregates generating some spring action. Moreover, when using mechanical compaction (vibrating table), the finishing on the higher percentage samples (30\% and $40 \%)$ containing coarse rubber aggregate was very poor with the top surface of the sample becoming irregular as the lighter material (rubber) was surfacing during compaction. The compacted specimens were demoulded 24 hours after casting and placed in a steel tub of water, to cure at a minimum temperature of $20^{\circ} \mathrm{C}$ for 7 and 28 days respectively. A number of tests on the hardened mixes were then performed, including cube compressive strength (100mm and $70 \mathrm{~mm}$ cubes), split-cylinder tensile strength, static modulus of elasticity of beams in compression and flexural strength test. The stress-strain behaviour of the cube samples was also continuously monitored during the compression tests, using a load cell and a displacement transducer connected to the ram. To assess repeatability, three specimens were tested for each mix. These gave repeatable results. The following sections show average values for each rubber percentage and test results.

\section{EXPERIMENTAL RESULTS}

\subsection{Workability of fresh concrete (Slump test)}

Figure 2 shows average results for each rubber percentage from the slump test. These showed that most mixes for the rubber sizes and percentages used in this study, with the exception of the $40 \%$ mixes for either fine or coarse aggregates and the 30\% mix for fine aggregates, had slump values corresponding to high to normal workability levels. In fact, for small percentages of rubber $(10 \%)$ the workability based on slump results comparable with those of the control mixes (0\%). This is consistent with results reported by Raghavan et al., (1998) for mortars containing rubber particles. With further increase in rubber content, for both the fine and coarse rubber specimens, the mix became stiffer and less workable, which was reflected in the significant decrease in slump values. The $40 \%$ coarse rubber tire mix in particular had too low slump values and was manually unworkable. The addition of fine aggregate rubber from $10 \%$ up to $40 \%$ rubber content maintained a linear decrease in slump values. This was not the case for the coarse aggregate rubber content which experienced a decrease of about $50 \%$ from a $10 \%$ rubber content to a $20 \%$ rubber content, a very small decrease in slump between $20 \%$ and $30 \%$ of rubber aggregate and then again a large decrease of about $33 \%$ between $30 \%$ and $40 \%$ of rubber aggregate. No particular trend was obvious as to whether the CRA or FRA mixes were more workable.

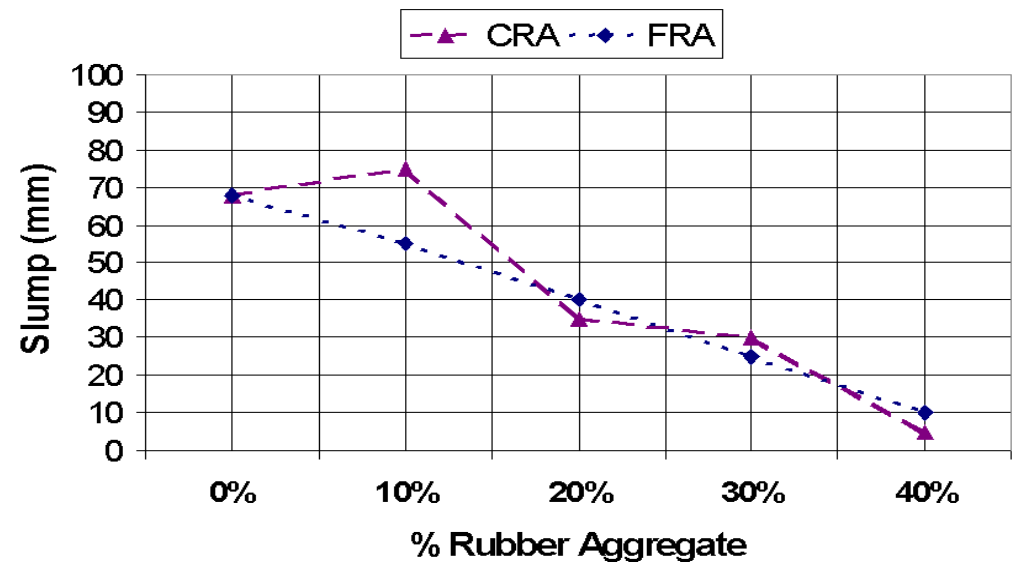

Figure 2. Average slump test results for each rubber percentage 


\subsection{Density}

Figures 3(a) and 3(b) show respectively the average densities for the 7 and 28 day-cured specimens prepared for cube compressive strength testing. From the figures it can be seen that density reduces by the addition of rubber aggregates whether these are fine or coarse. In most cases, for the same rubber content the fine rubber aggregate mixes had lower densities than those containing coarse rubber aggregate. The general density reduction was to be expected due to the low specific gravity of the rubber aggregates with respect to that of the mineral aggregates. The reduction in density can be a desirable feature in a number of applications, including architectural applications such as nailing concrete, false facades, stone backing and interior construction (Siddique and Naik, 2004) as well as precast concrete blocks and slabs.

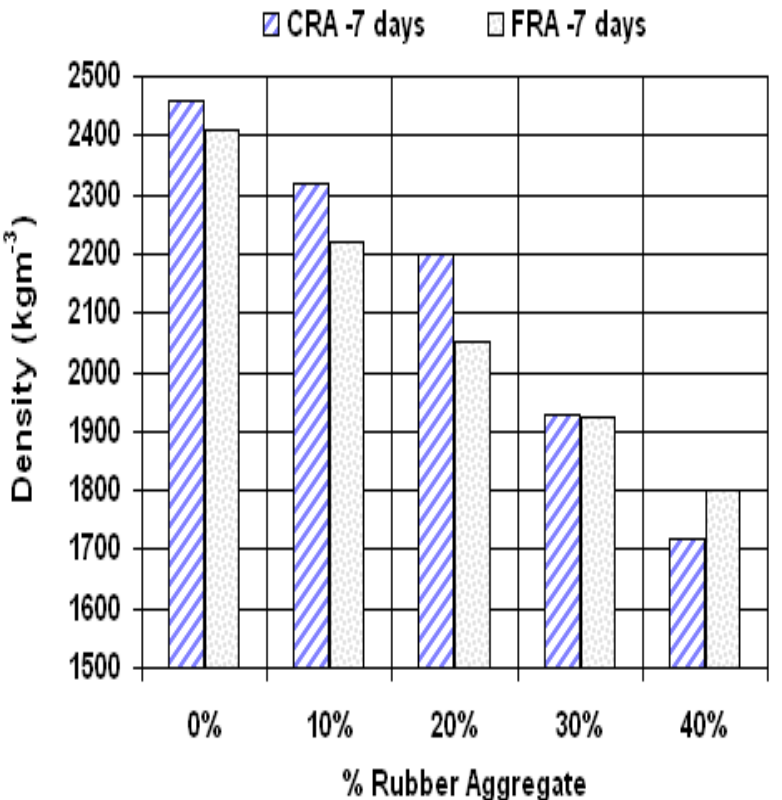

(a)

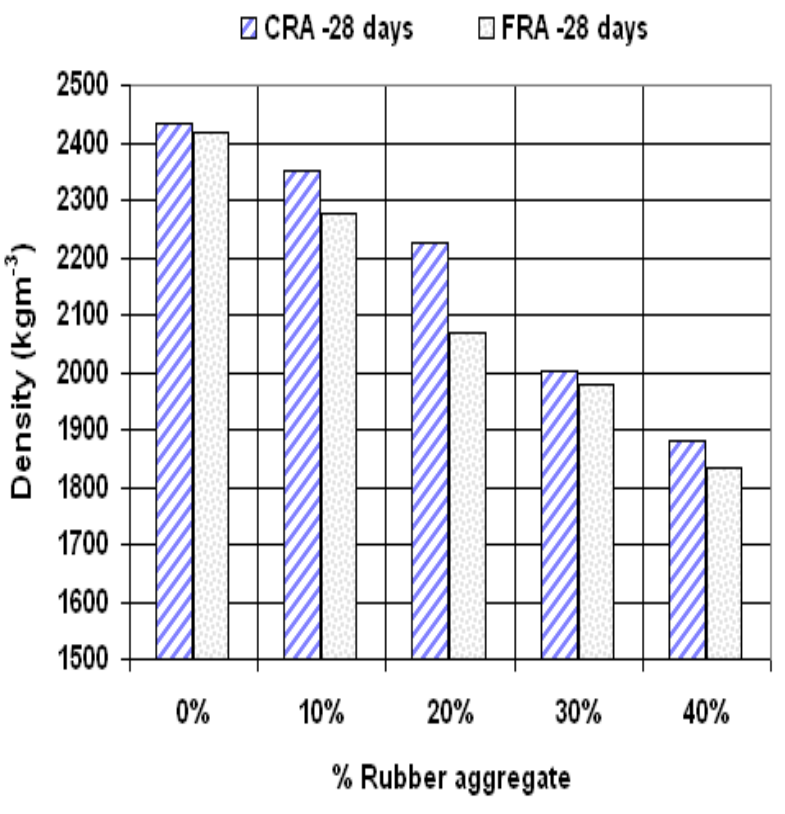

(b)

Figure 3. Density variation with rubber content (a) 7-day curing; (b) 28-day curing

\subsection{Cube compressive strength tests}

These were performed in a Losenhausen (3MN) compression machine according to BS EN 12390-3:2002 (BSI, 2002). Figure 4(a) represents the relationship between average cube compressive strengths and the percentage of rubber aggregate for 7 and 28 days of curing respectively. It can be seen that there is a very considerable loss in strength with respect to the average results of the control mixes. The loss was greater with increasing tyre aggregate percentage, amounting to $94 \%$ of the control mix strength for the $40 \%$ rubber content. The strength losses with respect to the average control mix strengths are represented in Table 1.

Table 1. Average compressive strength loss for mixes containing rubber aggregate

\begin{tabular}{|l|l|l|l|l|l|l|l|l|}
\hline \multirow{2}{*}{$\begin{array}{c}\text { Curing } \\
\text { time } \\
\text { (days) }\end{array}$} & \multicolumn{9}{|c|}{ CRA } & \multicolumn{9}{|c|}{ Compressive strength loss } \\
\cline { 2 - 9 } & $\mathbf{1 0 \%}$ & $\mathbf{2 0 \%}$ & $\mathbf{3 0 \%}$ & $\mathbf{4 0 \%}$ & $\mathbf{1 0 \%}$ & $\mathbf{2 0 \%}$ & $\mathbf{3 0 \%}$ & $\mathbf{4 0 \%}$ \\
\hline $\mathbf{7}$ & $53 \%$ & $76.6 \%$ & $87.5 \%$ & $94.3 \%$ & $32 \%$ & $60 \%$ & $82.1 \%$ & $89 \%$ \\
\hline $\mathbf{2 8}$ & $60.8 \%$ & $77.9 \%$ & $89.6 \%$ & $92.6 \%$ & $40.9 \%$ & $68.3 \%$ & $81.8 \%$ & $88.3 \%$ \\
\hline
\end{tabular}

In this study it was found that for the same percentage of tyre rubber aggregate, coarse rubber aggregate had a higher compressive strength, than concrete containing finer rubber aggregate, which is consistent with Fattuhi and Clark (1996) but contradicts Eldin and Senouci (1993) and Topçu (1995). The relationship between the reduction in compressive strength and the rubber aggregate percentage was found to be nonlinear. It is noticeable that as opposed to the average values of the control mixes, the mixes with rubber aggregate showed very little increase in the compressive strengths between the $7^{\text {th }}$ and the $28^{\text {th }}$ day of curing (with the only exception of the $10 \%$ coarse rubber aggregate mix), which is consistent with results 
from other researchers (Eldin and Senouci, 1993). This is particularly true for the fine rubber aggregate mixes. The plot of compressive strength versus density (Figure 4(b)) indicates an exponential drop of strength with density in the concrete with rubber mixes. The large losses in compressive strength imply that rubber percentages above 10\%-20\% would not be suitable for most structural applications, where high compressive strengths are required. However this type of concrete could be used in low-strength-concrete applications e.g. sidewalks, driveways and selected road construction applications (Eldin and Senouci, 1993).

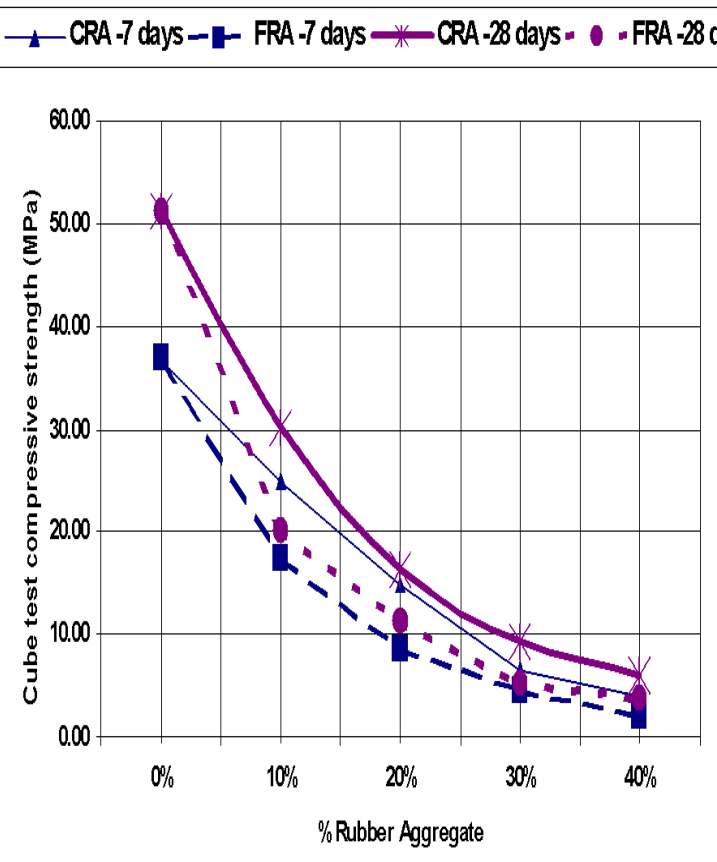

(a)

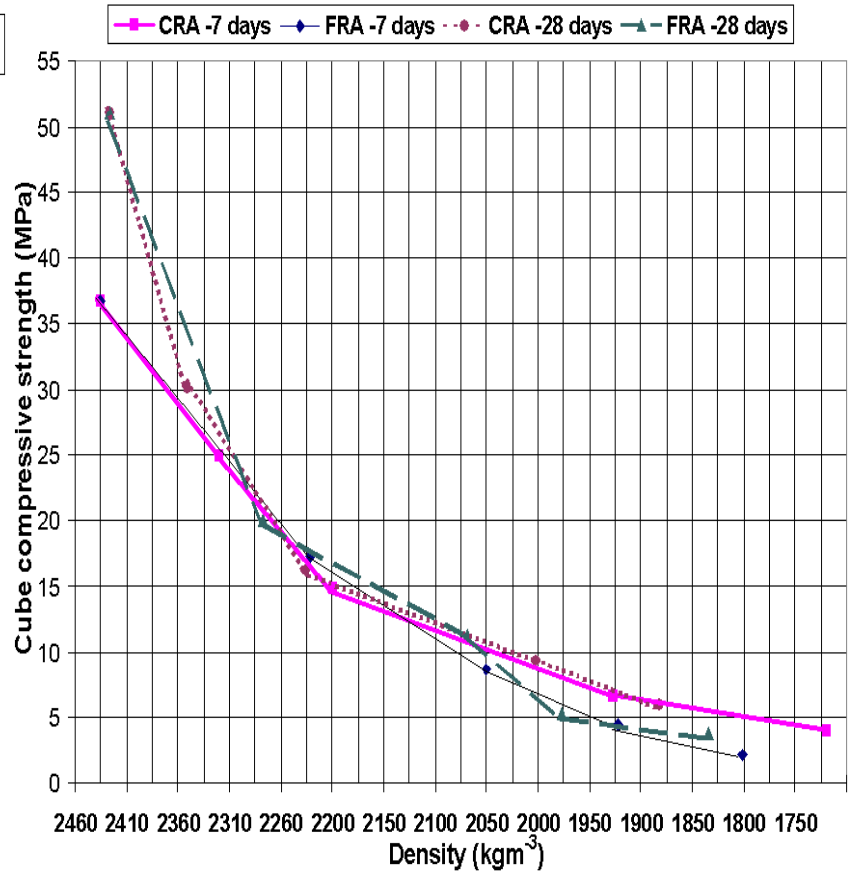

(b)

Figure 4. Compressive strength variation: (a) with rubber content; (b) with density

Direct comparisons of \% losses with other researchers' results are not possible as cubes (and/or cylinders) of various sizes were used in other investigations. It is known that different shape and size of specimens influence the compressive strength of concrete. Moreover, rubber aggregate of different type, origin, shapes, sizes and grading was used across investigations. However the reduction in compressive strength due to rubber aggregate is consistent across the literature. A number of possible explanations have been suggested in the literature for this loss of strength. This has usually been attributed to the fact that the rubber particles act as voids in the cement matrix due to the lack of adhesion between the rubber and the cement matrix. It was also suggested that the lower specific gravity of the rubber particles compared to the cement paste causes cracks around the rubber particles to appear quickly upon loading which accelerates the failure of the specimens (Khatib and Bayomy, 1999). Conversely, Chou et al., (2007) attributed the loss of strength to the heterogeneous, hydrophobic rubber particles, leading to local imperfections in the hydration of cement and hence locally weaker concrete. This suggestion was supported by microscopic studies showing that the rubber particles distributed the water transfer to create channels prone to cracking, thus causing a loss in compressive strength.Due to the low compressive strengths of the mixes containing rubber aggregates which would not be acceptable in most cases, the following sections will present results for the rest of the tests for the mixes containing $10 \%$ of rubber aggregate only, as these showed the best compressive strength values of all mixes containing rubber aggregate.

\subsection{Split cylinder tensile strength}

Similar trends were found for the split tensile strength of the mixes which was also reduced with rubber aggregate content (see Figure 5). The FRA mixes showed slightly better tensile properties than the CRA mixes, which is consistent with findings by Eldin and Senouci (1993). The losses in tensile strength upon the addition of rubber were however less pronounced than the losses in compressive strength, which is also consistent with Eldin and Senouci (1993). These amounted to a) $23.8 \%$ for the CRA and $20.6 \%$ for the FRA and b) $32.5 \%$ loss for the CRA and $29.9 \%$ for the FRA (with respect to the average values of the control mixes) for the 7 and 28 days of curing respectively. It was observed that upon splitting, the rubber 
particles seemed to hold the two parts of the concrete specimen together although the specimen had technically failed (this is consistent with observations of the cube compression specimen failure).

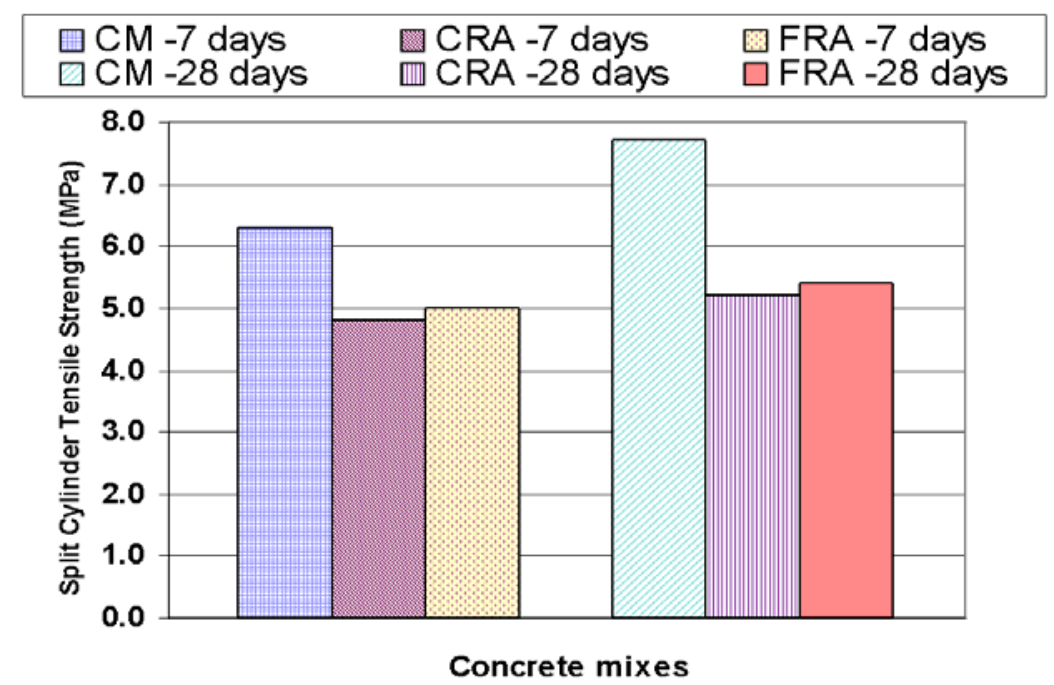

Figure 5. Average split cylinder tensile strengths

\subsection{Static Modulus of Elasticity $\mathrm{E}_{\mathrm{c}}$ (beam tests)}

This was calculated from beams of $500 \mathrm{~mm}$ length and a section of $100 \mathrm{~mm} \times 100 \mathrm{~mm}$ according to BS 1881-121:1983 (BSI, 1983). Figure 6 shows indicative average $E_{c}$ values of beams made of $C M$ and beams with 10\% CRA and 10\% FRA respectively (cured for 28 days). It is noted that the modulus of elasticity is reduced upon the addition of rubber aggregate, especially for FRA, implying a loss in stiffness, which would result in increased deflections of elements built with concrete containing rubber aggregate.

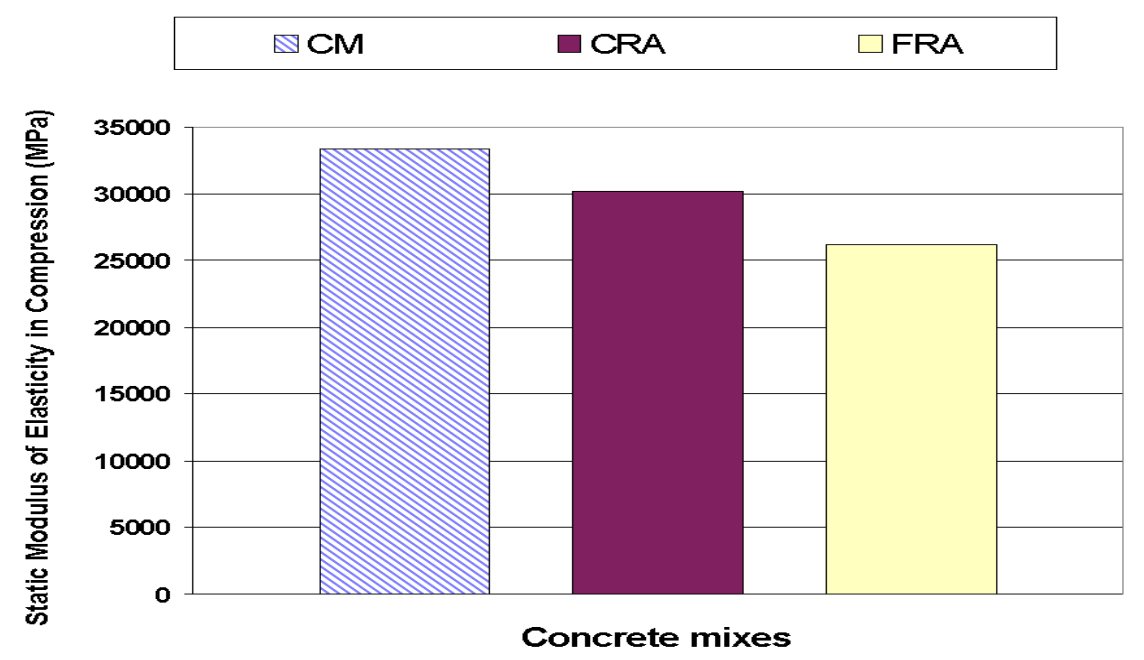

Figure 6. Average static modulus of elasticity $E_{c}$ values from 28-day cured beams

\subsection{Flexural strength (Modulus of rupture)}

After testing for the static modulus of elasticity the same beams were used to determine the modulus of rupture. This consisted in two-point flexural strength tests according to BS EN 12390-5:2000 (BSI, 2000c). This test concerns strength in tension of a beam or slab and shows when cracking will develop upon bending. It is therefore relevant for structures such as highway and airfield pavements which are designed on the basis of flexural strength of concrete, as in this application concrete elements are loaded in bending rather than axial tension. A slight reduction in the modulus of rupture (MoR) for both CRA and FRA samples, was observed in comparison to the control mixes (see Figure 7). FRA beams showed higher MoR than CRA beams. However the reduction is much smaller compared to other properties. 


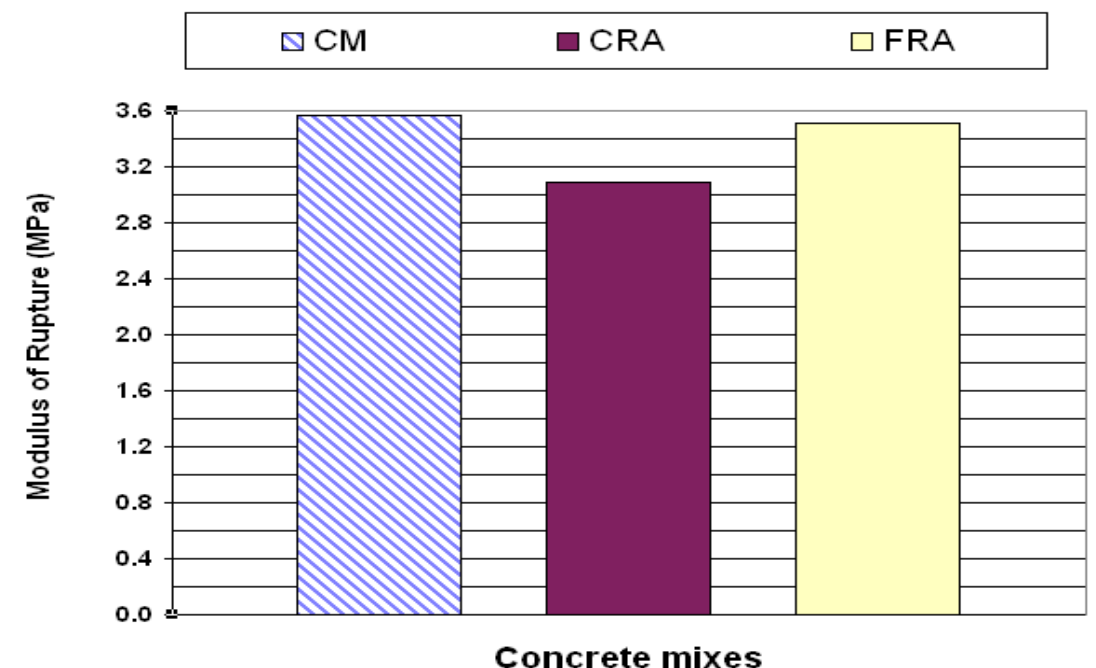

Figure 7. Average modulus of rupture values from 28-day cured beams

\subsection{Stress-strain behaviour upon uniaxial compression}

Figure 8 shows indicative results of stress-strain behaviour upon uniaxial compression. These represent results from $70 \mathrm{~mm}^{3}$ cube specimens containing fine rubber aggregates at various percentages. From the figure it can be seen that the control mix achieved generally higher strains at the peak stresses but the curve shows a much steeper descending branch in comparison to those of the stress-strain curves of mixes with rubber. The $20 \%$ and especially $30 \%$ rubber mixes do not exhibit a real peak, with the $30 \%$ FRA curve showing a prolonged plateau throughout the straining of the material. This shows evidence of a ductile fracture behaviour as well as an ability to support loads after cracks were generated. This behaviour, consistent with the ability of the rubber to flex under compression, was also reported by other researchers using different types of rubber and sizes of specimens (the exact stress-strain curves are specimen size dependent). The elastic modulus of rubber aggregate mixes is shown to be reduced, which is consistent with the reduction of $E_{c}$ from beam tests.

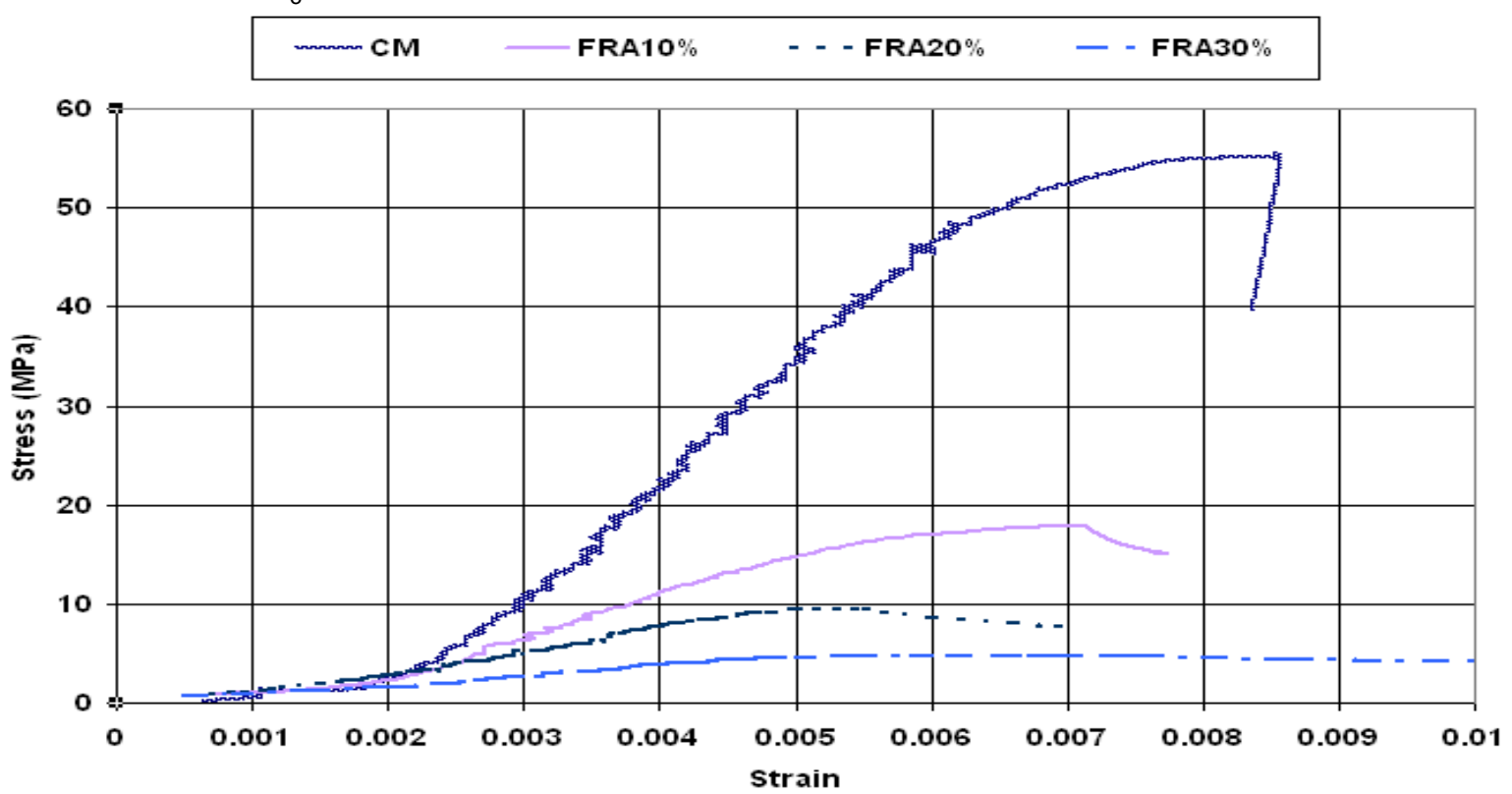

Figure 8. Indicative stress-strain results upon uniaxial compression

\section{DISCUSSION}

The results showed that concrete with rubber aggregate contents higher than $10 \%$ by mass would be unacceptable for primary structural elements. However there is a number of structural applications of medium to low strength requirements for which this material would be acceptable in terms of strength. For instance, a number of recent studies pointed out that concrete rubber aggregate could be used in the production of concrete blocks or other precast concrete units and have the advantage of a lower unit weight 
over usual concrete mixes. Concrete blocks are available in compressive strengths usually ranging from 2.8MPa to $35 \mathrm{MPa}$ (solid) and $2.8 \mathrm{MPa}$ to $20 \mathrm{MPa}$ (cellular and hollow), i.e. strengths which were shown to be achievable by concrete including rubber aggregates. Precast concrete units are produced under factory conditions enabling better quality control, hence making the large scale industrial production of the concrete with rubber aggregate feasible. These units are one of the main outlets of the concrete construction industry. For example, recent market surveys indicated that out of the $£ 1.8 \mathrm{bn}$ per annum spent in the UK on concrete products, $£ 600 \mathrm{~m}$ is building blocks and bricks and $£ 400 \mathrm{~m}$ is prefabricated structural components, including non-primary structural applications (Cairns et al., 2004). Therefore, considering the rates of production of these units, it appears that even if small percentages of rubber aggregate were included in these concrete products, this could lead to important reductions in the amount of waste tyre rubber. Possible applications of precast concrete units with rubber aggregate include amongst other partition walls, concrete blocks for architectural applications, some cases of slabs on soil, culverts, sidewalks, driveways and some road construction applications. A number of feasible non-structural concrete products including rubber aggregates can also be identified, for instance concrete fences and poles, foundation pads for machinery etc. It also seems possible to increase the strength of concrete with rubber aggregates using various methods suggested in the literature. These include soaking and washing rubber particles with water to remove impurities which could affect the strength of concrete (Eldin and Senouci, 1993), pretreatment in an alkaline solution, usually ( $\mathrm{NaOH})$, and chemical modification of the rubber particles by mild oxidisation carried out with hot air/steam in a fluidised bed reactor. Both latter treatments make the surface more hydrophilic, and enhance adhesion with concrete matrix while increasing water transfer rate and hydration at the interface of rubber with cement (Chou et al., 2007). Optimisation of mix design, use of different type of cement (other than Ordinary Portland Cement) and the incorporation of chemical and mineral admixtures can also be used to increase strength (Siddique and Naik, 2004). Any methods of strength improvement should consider costs, as well as whether the method is practical for a larger scale concrete production as opposed to laboratory trials. The suggested pretreatment processes mentioned earlier are however simple and likely to be economically viable and practicable, especially if applied for precast concrete units which are produced under factory conditions. Other than compressive strength, durability of concrete is also an important factor to consider. Rubber exposed in highly alkaline media for four months was found to deteriorate only slightly, suggesting that the durability of concrete would not be greatly affected upon rubber inclusion (Huynh and Raghavan, 1997).

An important factor when dealing with the acceptability of recycled materials is the cost versus the gained benefits. An investigation to the cost consideration of rubberised concrete was carried out by Cairns et al., (2004). This showed that at the time of the investigation, recycled rubber aggregates for concrete were more expensive than the mineral aggregates to be replaced (even when including the added UK Aggregate Levy tax in the costs of the natural aggregate materials). This could present a difficulty for the acceptance of rubberised concrete based on cost issues. The authors claimed however that the economics of using recycling rubber in concrete (including the production costs) would be expected to change as the market potential of this product develops and the demand of recycled rubber increases. The authors also pointed out that the processing requirements for rubber aggregate used in concrete are less stringent than for other applications, which would further reduce the cost for rubberised concrete block production and hence giving good prospects for this application (Cairns et al., 2004). This shows promise for the future commercial application of rubber in a large range of concrete products.

\section{CONCLUSIONS}

From the present experimental study and literature review it can be concluded that despite the observed lower values of the mechanical properties of concrete there is a potential large market for concrete products in which inclusion of rubber aggregate would be feasible. These can also include non primary structural applications of medium to low strength requirements, benefiting from other features of this type of concrete. Even if rubber tyre aggregate was used at relatively low percentages in concrete, the amount of waste tyre rubber could be greatly reduced due to the very large market for concrete products worldwide. Therefore the use of discarded tyre rubber aggregates in concrete shows promise for developing an additional route for used tyres.

\section{ACKNOWLEDGEMENTS}

This paper is an extended and modified version of a paper presented in CEST10 conference (September 2007). All tests described in the paper were carried out at the Concrete Laboratory of London South Bank University 
during 2006-2007. Assistance with the laboratory work, provided by David Metcalfe and Paul Elsdon (London South Bank University) is gratefully acknowledged.

\section{REFERENCES}

- Ali N.A., Amos A.D. \& Roberts M. (2000) Use of ground rubber tires in Portland cement concrete. In: Proceedings of the International Conference:Concrete 2000 University of Dundee, Scotland,UK.Vol.2, pp. 379-390.

- Bateman J. (2002), Heyope Tyre Tip, Powys (online) Environment Agency Wales, Available from: http://www.environment-agency.gov.uk/regions/wales/issueswales/ Accessed 20/3/07.

- British Standards Institution (BSI) (1983), BS 1881-121:1983: Testing concrete -Part 121: Method for determination of static modulus of elasticity in compression, BSI, London.

- British Standards Institution (BSI) (1992), BS 882:1992: Specification for aggregates from natural sources for concrete, BSI, London.

- British Standards Institution (BSI) (1997), BS 5238-1:1997: Concrete-Part 1: Guide to specifying concrete, BSI, London.

- British Standards Institution (BSI) (2000a), BS EN 12350-2:2000: Testing fresh concrete. Part 2: Slump test, BSI, London.

- British Standards Institution (BSI) (2000b), BS EN 12390-6:2000: Testing hardened concrete —Part 6: Tensile splitting strength of test specimens, BSI, London.

- British Standards Institution (BSI) (2000c), BS EN 12390-5:2000: Testing hardened concrete —Part 5: Flexural strength of test specimens, BSI, London.

- British Standards Institution (BSI) (2002), BS EN 12390-3:2002: Testing hardened concrete —Part 3: Compressive strength of test specimens, BSI, London.

- Cairns R., Kew H.Y., Kenny M.J. (2004), The Use of Recycled Rubber Tyres in Concrete Construction, Final Report, University of Strathclyde, Glasgow (online) Available from: http://www.veoliatrust.org/docs/The use of recovered tyres.pdf, Last accessed: 3/09/08.

- Chou L.H., Chun-Ku L., Chang J-R., Lee M.T. (2007) Use of waste rubber as concrete additive, Waste Management Research, 25(1), 68-76.

- Eldin N.N. and Senouci A.B. (1993), Rubber-tire particles as concrete aggregates, ASCE Journal of Materials in Civil Engineering , 5(4), 478-496.

- Fattuhi N.I. and Clark L.A. (1996), Cement-based materials containing shredded scrap truck tyre rubber, Construction and Building Materials, 10(4), 229-236.

- Huynh H. and Raghavan D. (1997), Durability of simulated shredded rubber tire in highly alkaline environments, Advanced cement based materials, 6(3-4),138-143.

- Khatib Z.K. and Bayomy F.M. (1999) Rubberized Portland cement concrete, ASCE Journal of materials in civil engineering, 11(3), 206-213.

- Raghavan D., Huynh H. and Ferraris C.F. (1998), Workability, mechanical properties and chemical stability of a recycled tire rubber-filled cementitious composite, Journal of Materials Science 33(7), 1745-1752.

- Siddique R. and Naik T.R. (2004), Properties of concrete containing scrap-tyre rubber - an overview, Waste Management, 24(6), 563-569.

- Topçu I.B. (1995) The properties of rubberised concretes, Cement and Concrete Research, 25(2), 304-310. 